\title{
Increased concentrations of both NMDA receptor co-agonists D-serine and glycine in global ischemia: a potential novel treatment target for perinatal asphyxia
}

\author{
Sabine A. Fuchs $\cdot$ Cacha M. P. C. D. Peeters-Scholte \\ Martina M. J. de Barse • Martin W. Roeleveld • \\ Leo W. J. Klomp · Ruud Berger · Tom J. de Koning
}

Received: 28 April 2011/Accepted: 13 September 2011/Published online: 23 September 2011

(C) The Author(s) 2011. This article is published with open access at Springerlink.com

\begin{abstract}
Worldwide, perinatal asphyxia is an important cause of morbidity and mortality among term-born children. Overactivation of the $N$-methyl-D-aspartate receptor (NMDAr) plays a central role in the pathogenesis of cerebral hypoxia-ischemia, but the role of both endogenous NMDAr co-agonists D-serine and glycine remains largely elusive. We investigated D-serine and glycine concentration changes in rat glioma cells, subjected to oxygen and glucose deprivation (OGD) and CSF from piglets exposed to hypoxiaischemia by occlusion of both carotid arteries and hypoxia. We illustrated these findings with analyses of cerebrospinal fluid (CSF) from human newborns affected by perinatal asphyxia. Extracellular concentrations of glycine and D-serine were markedly increased in rat glioma cells exposed to OGD, presumably through increased synthesis from L-serine. Upon reperfusion glycine concentrations normalized and D-serine concentrations were significantly
\end{abstract}

S. A. Fuchs $(\bowtie) \cdot$ M. M. J. de Barse - M. W. Roeleveld .

L. W. J. Klomp · R. Berger

Department of Metabolic and Endocrine Diseases,

University Medical Center Utrecht, Postbox 85090,

3508 AB Utrecht, The Netherlands

e-mail: S.Fuchs@umcutrecht.nl

S. A. Fuchs - M. M. J. de Barse - M. W. Roeleveld ·

L. W. J. Klomp · R. Berger

Department of Biomedical Genetics,

University Medical Center Utrecht, 3508 AB

Utrecht, The Netherlands

S. A. Fuchs - T. J. de Koning

Department of Metabolic Diseases, University Medical

Center Utrecht, 3508 AB Utrecht, The Netherlands

C. M. P. C. D. Peeters-Scholte

Department of Pediatric Neurology, Leiden University

Medical Center, 2333 ZA Leiden, The Netherlands lowered. The in vivo studies corroborated the finding of initially elevated and then normalizing concentrations of glycine and decreased D-serine concentrations upon reperfusion These significant increases of both endogenous NMDAr co-agonists in combination with elevated glutamate concentrations, as induced by global cerebral ischemia, are bound to lead to massive NMDAr activation, excitotoxicity and neuronal damage. Influencing these NMDAr co-agonist concentrations provides an interesting treatment target for this common, devastating and currently poorly treatable condition.

Keywords D-Serine - Glutamate $\cdot$ NMDA receptor . Perinatal asphyxia $\cdot$ Ischemia

\section{Introduction}

Perinatal asphyxia is the consequence of impaired blood supply between mother and fetus, leading to insufficient delivery of oxygen, glucose and other blood-borne fuels to fetal organs, including the brain. The short-term clinical consequences include persistent low Apgar scores, multiorgan failure and neurological sequelae. In the long-term, this might result in cerebral palsy, mental retardation, visual and acoustic impairment and epilepsy (Robertson et al. 1989; Shankaran et al. 1991). In spite of improvements in perinatal care, the incidence and outcome of perinatal asphyxia remain relatively unchanged. Of the yearly estimated 4 million neonatal deaths worldwide, approximately 1 million is caused by perinatal asphyxia (Lawn et al. 2005). Of infants with moderate encephalopathy, $10 \%$ die, and $30 \%$ of those who survive, have disabilities. Among infants with severe encephalopathy, $60 \%$ die, and many, if not all survivors are handicapped 
(Robertson et al. 1989; Shankaran et al. 1991). Treatment is currently aimed at supportive intensive care, recently combined with hypothermia (Selway 2010).

It has been firmly established that excessive excitation of the $N$-methyl-D-aspartate receptor (NMDAr) plays a central role in the pathogenesis of hypoxic-ischemic damage, especially in the developing brain (Sattler and Tymianski 2001). The NMDAr requires simultaneous binding by glutamate and a co-agonist for activation. It had long been assumed that glycine was the endogenous co-agonist. However, recent studies have shown that D-serine is the main endogenous co-agonist for most NMDAr subtypes in most brain areas (Mothet et al. 2000). Since NMDArs appear not to be saturated during physiological conditions (Bergeron et al. 1998), elevations in glycine or D-serine concentrations may lead to increased toxicity during pathological conditions, such as hypoxia-ischemia. NMDAr activation and D-serine concentrations are strongly developmentally regulated (Fuchs et al. 2006), implying a specific role in central nervous system (CNS) development. Alterations in D-serine concentrations and NMDAr activation during this intense period of embryonic and early postnatal CNS development, induced for instance by perinatal asphyxia, may therefore be particularly deleterious. The synthesizing (Wolosker et al. 1999) and metabolizing (Molla et al. 2006) enzymes of D-serine and glycine have been characterized (Fig. 1). By pharmacological manipulation, this might yield new potential candidates for pharmacological intervention after perinatal asphyxia.

Despite this exciting hypothesis, most research has focused on glutamate, and the contribution of D-serine and glycine to the pathogenesis of perinatal asphyxia remains largely elusive. Therefore, we investigated D-serine and glycine concentration changes in different models for global ischemia.

\section{Cell cultures}

We subjected rat glioma cells to oxygen-glucose deprivation (OGD), a commonly used in vitro model for global ischemia, although the duration and depth of oxygen and glucose deprivation vary between studies (Jones et al. 2004). Although neurons are far more susceptible to ischemic brain damage than neighboring astrocytes, glioma cells were studied, because of emerging evidence that astrocytes contribute substantially to neuronal fate in cerebral hypoxia-ischemia (Rossi et al. 2007). By studying astrocytes in isolation, the direct effects of OGD on astrocytes could be visualized without the effects of stressed neuronal cells complicating interpretation.

\section{Piglets}

Analysis of CSF from piglets exposed to hypoxia-ischemia by occlusion of both common carotid arteries, combined with hypoxia. Piglet brains correspond well with those of term-born neonates (Dobbing and Sands 1979), and this animal model is commonly used to study global ischemia (Fritz et al. 1999; Peeters-Scholte et al. 2002).

We illustrated these findings with cerebrospinal fluid (CSF) analyses from a small number of newborns with and without perinatal asphyxia. Despite being a global marker
Fig. 1 Pathways involved in L-serine and D-serine biosynthesis, catabolism and exogenous sources. 3-PGDH 3-phosphoglycerate dehydrogenase,

3-PSP 3-phosphoserine phosphatase, SHMT serine hydroxymethyltransferase, $G C S$ glycine cleavage system, $S R$ serine racemase, $D A O$ D-amino acid oxidase

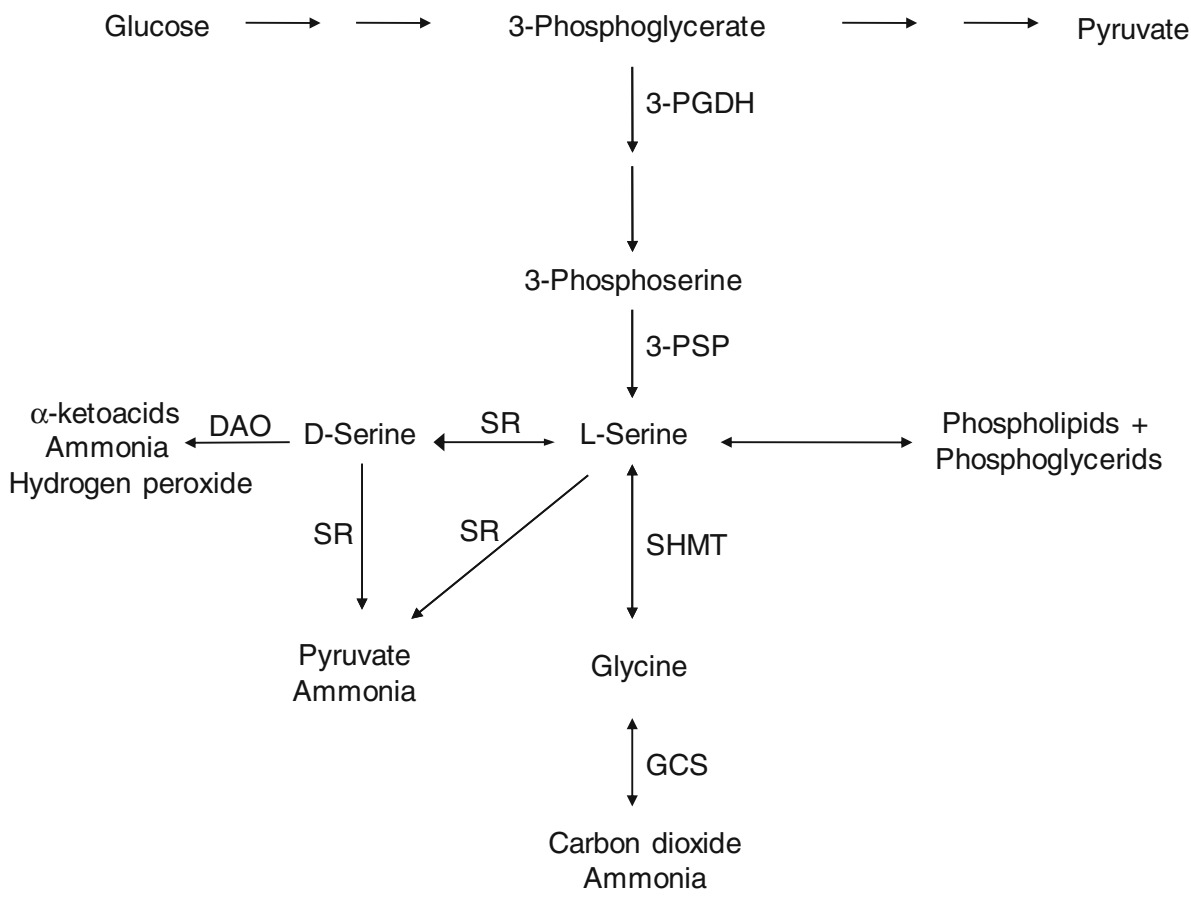


for concentration differences in brain regions, CSF is the most accessible CNS marker in these critically ill newborns.

In all models, we found consistent time-dependent changes in D-serine and glycine concentrations upon hypoxia-ischemia and reperfusion. Together with the known increases in extracellular glutamate concentrations (Benveniste et al. 1984; Gucuyener et al. 1999; PukaSundvall et al. 1996; Ueda et al. 1992) after hypoxiaischemia, the increased concentrations of both NMDAr coagonists ought to lead to massive NMDAr activation, resulting in excitotoxicity and neuronal damage.

\section{Materials and methods}

Cell cultures

\section{Materials}

Rat glioma C6 cells were cultured in F-12 Kaighn's medium supplemented with $10 \%$ fetal calf serum and $100 \mu \mathrm{g} / \mathrm{ml}$ penicillin/streptomycin (all from Gibco Life Technologies, Invitrogen, Breda, The Netherlands). To create normoglycemic and hypoglycemic conditions, media identical in inorganic salt, amino acid and vitamin composition and only different in glucose content (RPMI 1640 BE-12 702F: 2,000 mg/l and BE-12 752F: 0 mg/l, Bio Whittaker, Breda, The Netherlands), supplemented with $10 \%$ fetal calf serum and $100 \mu \mathrm{g} / \mathrm{ml}$ penicillin/streptomycin (Gibco Life Technologies, Invitrogen, Breda, The Netherlands) were used. Hypoxia was applied by culturing samples in an in $\mathrm{VIVO}_{2}$ Hypoxia workstation 1000 (Biotrace International, Mid Glamorgan, UK), equipped with a Ruskinn gas mixer module $\mathrm{V}_{2}$ (Biotrace International, Mid Glamorgan, UK). Oxygen level was set at $1 \%, \mathrm{CO}_{2}$ at $5 \%$ and $\mathrm{H}_{2}$ at $0 \%$.

\section{Experimental design}

The experiment was started by washing $6 \times 6$ well plates (C2-C3 and S2-S3 started on day 1; C1 and S1 started $24 \mathrm{~h}$ (h) later, Fig. 2) of near confluent glioma C6 cells twice with phosphate buffered saline and applying the experimental conditions (6 different samples per condition). A sample of the external medium was collected at the end of each condition and stored at $-20^{\circ} \mathrm{C}$ until analysis. This experiment ( 6 conditions; $n=6$ for each condition) was repeated on four different occasions.

\section{Quantitative amino acid determination}

D-Serine, L-serine and glycine concentrations were measured by stable isotope dilution gas and liquid

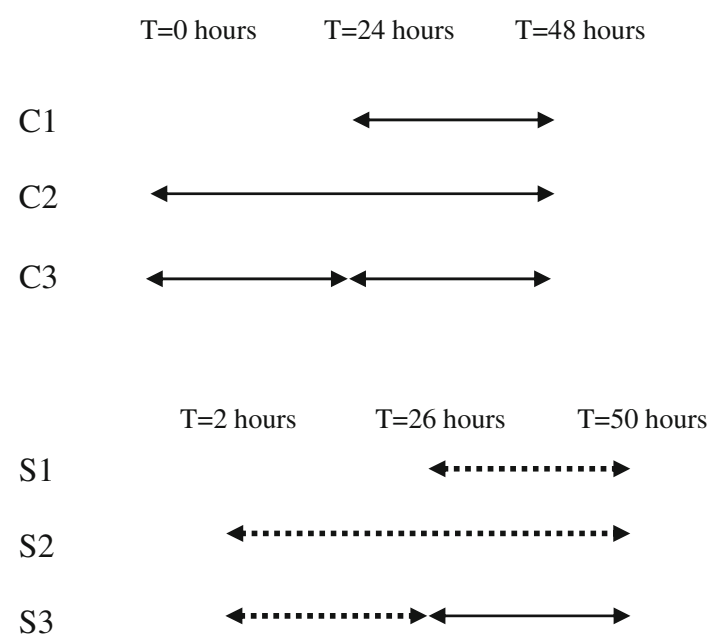

Fig. 2 Experimental design of the Glioma C6 studies. Straight line with arrows indicate normoxia and normoglycemia $\left(21 \% \mathrm{O}_{2}\right.$; RPMI 12-702 medium). Dotted line with arrows oxygen and glucose deprivation $\left(1 \% \mathrm{O}_{2}\right.$; RPMI 12-752 medium) Cl-C3 control 1-3; S1-S3 sample 1-3

chromatographic-mass spectrometric methods as described before (Fuchs et al. 2008).

Piglets

Seven newborn Dutch store piglets with a postnatal age range from 1 to 3 days were exposed to hypoxia-ischemia by occlusion of both common carotid arteries and reduction of the fraction of inspired oxygen for $1 \mathrm{~h}$ as described previously (Peeters-Scholte et al. 2002). CSF was withdrawn at $3 \mathrm{~h}(n=2)$ or $24 \mathrm{~h}(n=5)$ after the start of hypoxia-ischemia. CSF was also withdrawn in three control piglets, which underwent the same surgical procedure but were not exposed to hypoxia-ischemia. Experimental protocols were approved by the Animal Research Committee of the Utrecht University, The Netherlands.

Statistical analyses

Amino acid concentration differences between the external medium of glioma C6 cells and "fresh medium" (from the bottle, supplemented with fetal calf serum and penicillin/ streptomycin) were compared between experimental and control conditions using the unpaired Student's $t$ test. Similarly, amino acid concentrations in CSF from piglets $24 \mathrm{~h}$ after hypoxia-ischemia were compared with control CSF, using the unpaired Student's $t$ test. The level of significance was set at $p<0.05$. Since there was CSF of only two piglets $3 \mathrm{~h}$ after hypoxia-ischemia, these were not included in the statistical analyses but presented to show the trend of concentration changes. 


\section{Results}

Rat glioma C6 cells were incubated according to our experimental protocol (see "Materials and methods"). In control conditions, D-serine concentrations in external medium increased after $24 \mathrm{~h}$ to $+0.42 \mu \mathrm{M}$ (Fig. 3) and after $48 \mathrm{~h}$ to $+0.64 \mu \mathrm{M}$ ( $p<0.05$ when comparing $24 \mathrm{~h}$ with $48 \mathrm{~h}$ ), potentially through the release from vesicular storage (Hur et al. 2010; Martineau et al. 2008; Mothet et al. 2005). Glycine and L-serine concentrations decreased during $24-48 \mathrm{~h}$ of normal conditions, suggesting uptake by glioma cells.

Application of OGD for 24 or $48 \mathrm{~h}$ resulted in increases in $\mathrm{D}$-serine concentrations from $+0.42 \mu \mathrm{M}$ (control condition) to $+0.69 \mu \mathrm{M}$ at $24 \mathrm{~h}$ and from $+0.64 \mu \mathrm{M}$ (control condition) to $+0.91 \mu \mathrm{M}$ at $48 \mathrm{~h}$ ( $p<0.05$ in both cases). After OGD, glycine concentrations increased from $-78 \mu \mathrm{M}$ (control condition) to $+109 \mu \mathrm{M}$ at $24 \mathrm{~h}$ and from $-151 \mu \mathrm{M}$ (control condition) to $+175 \mu \mathrm{M}$ at $48 \mathrm{~h}(p \ll 0.01$ in both cases; $p<0.05$ when comparing 24-48 h OGD).

Interestingly, when simulating reperfusion by applying normoxia/normoglycemia (NO/NG) after 24-h OGD, D-serine concentrations were significantly lowered when compared to control conditions $[+0.66 \mu \mathrm{M}$ (control condition) vs. $+0.34 \mu \mathrm{M}(24 \mathrm{~h}$ OGD $+24 \mathrm{~h}$ NO/NG), $p<0.01]$. Concentrations of glycine normalized, by decreasing to a lesser extent than during control conditions $[-116 \mu \mathrm{M}$ (control condition) vs. $-52 \mu \mathrm{M}(24 \mathrm{~h}$ $\mathrm{OGD}+24 \mathrm{~h} \mathrm{NO} / \mathrm{NG})]$.

Concentrations of L-serine, the common precursor of D-serine and glycine, and other amino acids (including aspartate, another excitatory amino acid, data not shown) decreased after OGD and in the reperfusion experiment, but lesser than during control conditions, suggesting that
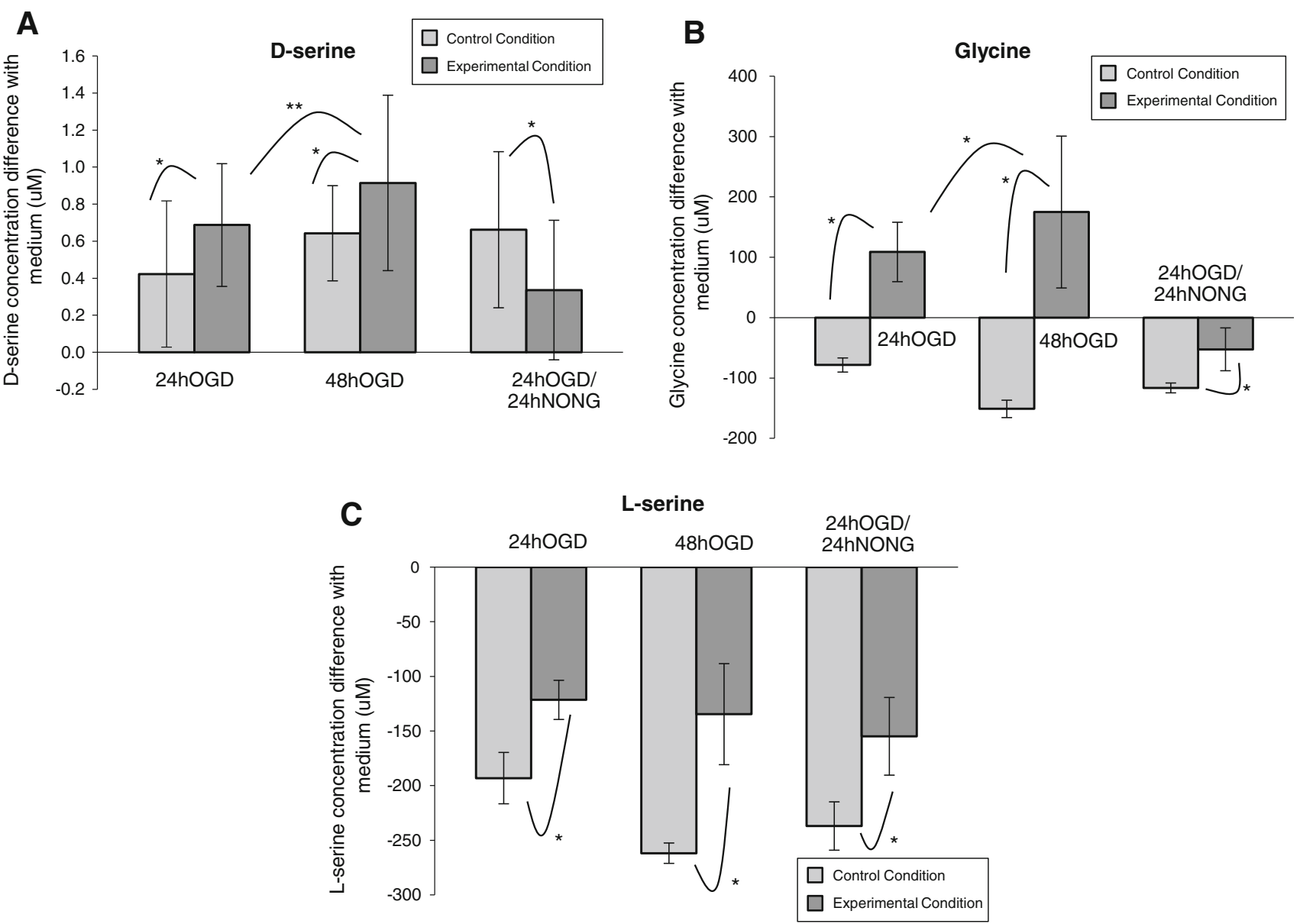

Fig. 3 Medium concentration differences of the NMDAr agonists D-serine, glycine and their common precursor L-serine after oxygen and glucose deprivation $(O G D)$ The figures represent the mean \pm standard deviation of the concentration differences of D-serine (a), glycine (b) and L-serine (c) between fresh medium (directly taken from the bottle, supplemented with fetal calf serum and penicillin/ streptomycin, as was used in the experiments) and the external medium after $24 \mathrm{~h}$ OGD, $48 \mathrm{~h}$ OGD, and $24 \mathrm{~h}$ OGD followed by $24 \mathrm{~h}$ normoxia/normoglycemia $(N O / N G)$. These graphs represent the mean of six different samples and six different controls during four different experiments. *Significant change with a $p$ value $<0.05$ and $* * 0.05<p<0.1$ 
the rise in D-serine and glycine is caused by specific synthesis and not mere efflux due to, for instance, increased cell wall permeability.

In order to gain insight into the mechanism responsible for the changes in D-serine and glycine concentrations, a fifth condition was added (similar to $\mathrm{S} 1$ and $\mathrm{C} 1$, Fig. 2) by addition of $3 \mathrm{mg}$ of the labeled stable isotope ${ }^{13} \mathrm{C}_{3}^{15} \mathrm{~N}$ L-serine (Cambridge Isotope Laboratories, Inc., Andover, USA) to $100 \mathrm{ml}$ medium (to a concentration of $285 \mu \mathrm{M}$ ), to which NO/NG, OGD, normoxia/hypoglycemia and hypoxia/normoglycemia was applied during $48 \mathrm{~h}$, because the effects were most evident after $48 \mathrm{~h}$ (Fig. 3). By labeling L-serine, the common endogenous precursor of D-serine and glycine, we investigated D-serine and glycine synthesis from L-serine by quantifying the resulting labeled D-serine and glycine (Table 1). In this experiment, D-serine concentrations remained unaffected by $48 \mathrm{~h}$ OGD when compared to NO/NG $(0.04 \mu \mathrm{M}$ and $0.03 \mu \mathrm{M}$, respectively, non-significant), but these concentrations were very low, nearing the limit of detection of the analytical method. Glycine concentrations increased significantly and markedly after $48 \mathrm{~h}$ OGD $(57.0 \mu \mathrm{M})$, when compared to control conditions $(34.3 \mu \mathrm{M}, p<0.01)$. Synthesis of labeled glycine after $48 \mathrm{~h}$ of control conditions is interesting when considering the decrease in total glycine concentrations in medium after $48 \mathrm{~h}$ (Fig. 3), implying simultaneous synthesis and use of glycine under normal conditions. Under $\mathrm{NO} / \mathrm{NG}$ conditions, D-serine synthesis accounted for $0.02 \%$ and glycine synthesis for $18 \%$ of $\mathrm{L}$-serine use. D-Serine synthesis from L-serine was not significantly increased by hypoxia, hypoglycemia or the combination $(0.05<p<0.1$ for OGD), but again, concentrations of labeled D-serine were very low for quantification with our analytical method. Glycine synthesis from L-serine almost doubled to $28 \%$ $(p<0.01)$ upon hypoxia, decreased to $4.6 \%(p<0.01)$ upon hypoglycemia and almost tripled to $51.5 \%(p<0.01)$ upon OGD.
Piglets

Three hours after starting hypoxia-ischemia, piglets showed an almost eightfold increase in glycine concentrations in CSF when compared to control piglets (Fig. 4). Glycine concentrations remained markedly increased (fourfold $p<0.05$ ) in CSF $24 \mathrm{~h}$ after starting hypoxiaischemia when compared to control piglets, but lesser than $3 \mathrm{~h}$ after hypoxia-ischemia (twofold reduction). D-Serine concentrations seemed to rise marginally $3 \mathrm{~h}$ after hypoxia-ischemia (but $n=2$ ), and were significantly reduced at $24 \mathrm{~h}$ when compared with control piglets $(40 \%$ reduction, $p<0.05)$. L-Serine concentrations appeared to increase in CSF $3 \mathrm{~h}$ after hypoxia-ischemia $(50 \%$, but again $n=2$ ) and were similar to control values $24 \mathrm{~h}$ after hypoxia-ischemia.

\section{Discussion}

Since perinatal asphyxia is an important contributor to neonatal mortality and morbidity with poor curative treatment options, this study was aimed to elucidate mechanisms of NMDAr-associated excitotoxicity in hypoxiaischemia in an attempt to yield novel treatment strategies. The necessity for NMDArs to be activated not only by glutamate, but also by glycine or D-serine may be regarded as a safety mechanism to prevent excitotoxicity. Our results imply that this safety mechanism fails in global cerebral ischemia, since we found that concentrations of both glycine and D-serine significantly increased during hypoxicischemic conditions. Furthermore, our studies provide further evidence that glia are relevant signaling partners and not merely supporting cells for neurons, as was long believed (Billard 2008; Halassa et al. 2007; Oliet and Mothet 2009; Panatier et al. 2006). In fact, glia do not only protect neurones by glutamate uptake, but our results show

Table 1 Changes in D-serine and glycine synthesis from L-serine after hypoxia, hypoglycemia and OGD

\begin{tabular}{|c|c|c|c|c|c|}
\hline & $\begin{array}{l}{ }^{13} \mathrm{C}_{3} \text { L-serine } \\
\text { use }(\mu \mathrm{M})\end{array}$ & $\begin{array}{l}{ }^{13} \mathrm{C}_{3} \text { D-serine } \\
\text { synthesis }(\mu \mathrm{M})\end{array}$ & $\begin{array}{l}{ }^{13} \mathrm{C}_{2} \text { glycine } \\
\text { synthesis }(\mu \mathrm{M})\end{array}$ & $\begin{array}{l}{ }^{13} C_{3} \text { D-serine synthesis/ } \\
{ }^{13} C_{3} \text { L-serine use }(\%)\end{array}$ & $\begin{array}{l}{ }^{13} \mathrm{C}_{2} \text { glycine synthesis/ } \\
{ }^{13} \mathrm{C}_{3} \text { L-serine use }(\%)\end{array}$ \\
\hline $\mathrm{NO} / \mathrm{NG}$ & $191.3(\mathrm{SD} 3.8)$ & $0.03(\mathrm{SD} 0.04)$ & 34.3 (SD 1.8) & $0.02(\mathrm{SD} 0.02)$ & $18.0(\mathrm{SD} 1.0)$ \\
\hline $\mathrm{HO}$ & $162.8(\mathrm{SD} 6.7)$ & $0.12(\mathrm{SD} 0.07)$ & $45.8(\mathrm{SD} 4.4)$ & $0.08(\operatorname{SD} 0.05, p=0.05)$ & $28.3(\operatorname{SD} 4.0, p<0.01)$ \\
\hline $\mathrm{HG}$ & 231.7 (SD 4.6) & $0.12(\mathrm{SD} 0.07)$ & $10.7(\mathrm{SD} 1.3)$ & $0.05(\mathrm{SD} 0.03, p=0.09)$ & $4.6(\operatorname{SD} 0.6, p<0.01)$ \\
\hline OGD & 111.7 (SD 10.8) & 0.04 (SD 0.06) & $57.0(\mathrm{SD} 3.6)$ & $0.04(\operatorname{SD} 0.06, p=0.51)$ & $51.5(\mathrm{SD} 7.4, p<0.01)$ \\
\hline
\end{tabular}

D-Serine and glycine synthesis from L-serine was studied by analysis of resulting ${ }^{13} \mathrm{C}_{3}$ D-serine and ${ }^{13} \mathrm{C}_{2}$ glycine concentrations in the medium upon addition of ${ }^{13} \mathrm{C}_{3} \mathrm{~L}$-serine. The table depicts medium concentration changes in ${ }^{13} \mathrm{C}_{3} \mathrm{~L}$-serine (added to a medium concentration of $285 \mu \mathrm{M}$ ), ${ }^{13} \mathrm{C}_{3}$ D-serine and ${ }^{13} \mathrm{C}_{2}$ glycine after rat glioma C6 cells were exposed to $48 \mathrm{~h}$ of NO/NG, hypoxia (HO), hypoglycemia (HG) or OGD ( $n=6$ for each condition). The last two columns represent the percentage of ${ }^{13} \mathrm{C}_{3}$ D-serine and ${ }^{13} \mathrm{C}_{2}$ glycine synthesis, respectively, of total ${ }^{13} \mathrm{C}_{3} \mathrm{~L}$-serine use and the $p$ value (Student's $t$ test) after comparison with the NO/NG condition ( $N=6$ for all conditions) 

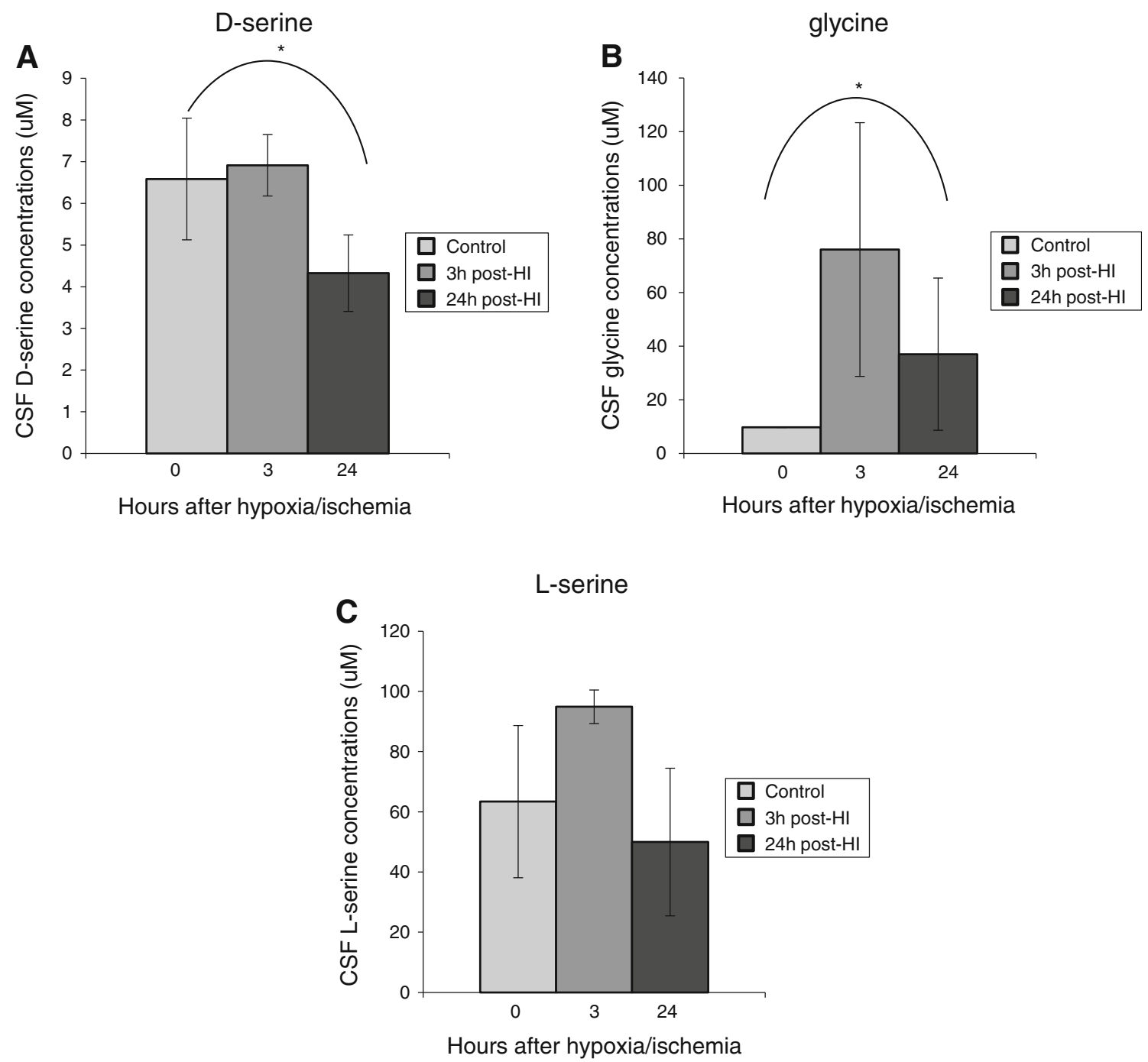

Fig. 4 D-Serine, glycine and L-serine concentrations in CSF from control piglets and 3 and $24 \mathrm{~h}$ after application of cerebral hypoxiaischemia CSF concentrations of D-serine (a), glycine (b), and L-serine (c) as determined by GC-MS in control piglets $(n=3), 3 \mathrm{~h}$ after start

that glia also contribute to neurotoxicity by increasing extracellular D-serine and glycine concentrations.

Both D-serine and glycine concentrations appear to rise through increased synthesis from L-serine. A central role for D-serine synthesis from L-serine by SR during OGD is evidenced by SR knock-out mice, displaying $90 \%$ reduced D-serine concentrations and decreased neurotoxicity and dramatically diminished infarct volume after middle cerebral artery occlusion (Mustafa et al. 2010). For glycine, we showed in our isotope studies that glycine synthesis from L-serine almost tripled from $18 \%$ under control conditions to $51.5 \%$ after OGD. Since use of labeled L-serine decreased after OGD, this might represent a specific shift of L-serine use towards glycine synthesis. However, the concentration differences might also in part be explained by ischemia-induced changes in re-uptake pumps, as have of hypoxia-ischemia $(H I)(n=2)$ and $24 \mathrm{~h}$ after start of hypoxiaischemia $(n=5)$. Changes between control piglets and $24 \mathrm{~h}$ after start of hypoxia-ischemia were statistically evaluated and *significant change with $p<0.05$

been described for glutamate (Huang et al. 1993). This was not specifically assessed in our study and would be interesting to investigate in future experiments.

The relative contribution of $\mathrm{D}$-serine and glycine to NMDAr-induced neuronal death following ischemia remains unclear. Addition of D-amino acid oxidase (DAO), the enzyme that degrades D-serine and not glycine, led to diminished cell death upon application of NMDA or OGD (Katsuki et al. 2004). Similarly, NMDA-elicited neurotoxicity in rat hippocampal slices was virtually abolished by complete removal of D-serine (Shleper et al. 2005). The effects of endogenous glycine could be observed only after simultaneous removal of endogenous D-serine and blockage of the glycine transporter GlyT1. Thus, although levels of glycine were tenfold higher than D-serine in this study, endogenous $\mathrm{D}$-serine might be the dominant co-agonist for 


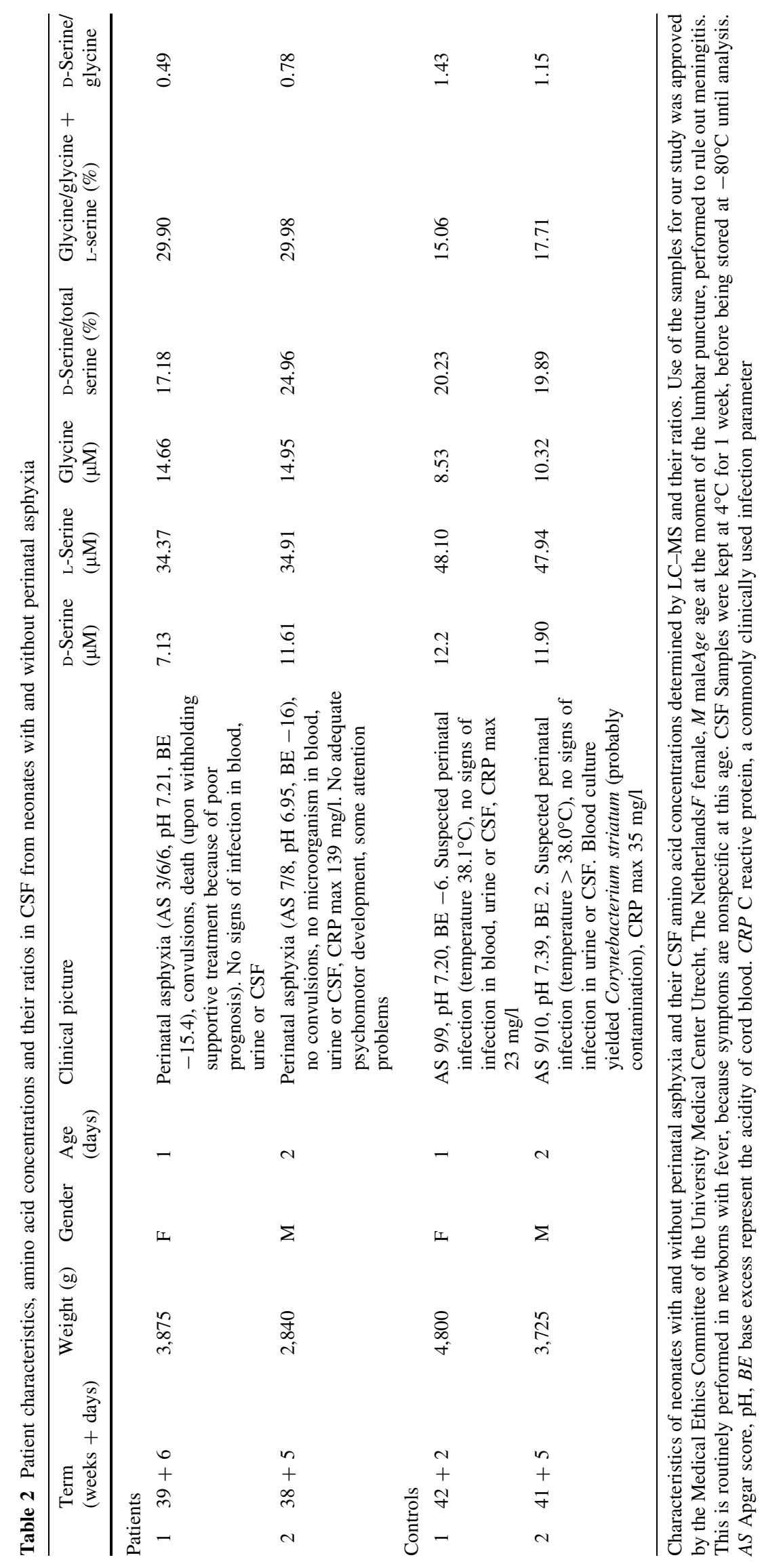


NMDA-elicited neurotoxicity (Shleper et al. 2005). This important role of D-serine in neurotoxicity following ischemia is confirmed by the dramatically diminished neurotoxicity and infarct volume in SR knock-out mice (Mustafa et al. 2010). Moreover, simultaneous elevation of both NMDAr co-agonists as seen in our experiments, in combination with the known increases in extracellular glutamate concentrations (Benveniste et al. 1984; Gucuyener et al. 1999; Puka-Sundvall et al. 1996; Ueda et al. 1992) must lead to NMDAr-associated excitotoxicity.

During the reperfusion phase, we observed increased but normalizing glycine concentrations in vitro and in vivo. This concurs with the few reports describing increased glycine concentrations in mammalian CSF or microdialysates after global ischemia (Baker et al. 1991; Phillis and Walter 1989; Roldan et al. 1999). Interestingly, we observed significantly reduced D-serine concentrations during the reperfusion phase, both in vitro and in vivo. This concurs with the finding of delayed transient decreases of SR (mRNA and protein) and D-serine in the ipsilateral temporoparietal mouse cortex after permanent focal ischemia (Wang and Zhu 2004). In accordance with the model of a safety mechanism, this reduction in D-serine concentrations during reperfusion might represent an attempt to compensate for increased NMDAr activity. Potentially, the elevated glycine concentrations contribute to this phenomenon, since glycine inhibits SR activity at these concentrations (Strisovsky et al. 2005).

This pattern of concentration changes induced by hypoxia-ischemia and reperfusion was consistent with the analyses performed in CSF withdrawn from human newborns with and without perinatal asphyxia $24-48 \mathrm{~h}$ after birth, thus representing the reperfusion phase (Table 2). Asphyxiated neonates displayed higher glycine concentrations and percentage glycine of the sum of L-serine and glycine (an indication for the amount of glycine synthesis from L-serine) and in the most serious case of asphyxia also lower D-serine concentrations and percentage D-serine of the sum of D- and L-serine (an indication for the quantity of D-serine synthesis from L-serine) than controls. The finding of alterations in the CSF, which represents just a global marker for changes in the CNS, emphasizes the magnitude of concentration changes of the NMDAr co-agonists in specific brain areas.

In conclusion, our results encourage the development of effective and safe drugs preventing NMDAr overactivation after global ischemia. Therapeutic agents for hypoxiaischemia, including competitive and non-competitive NMDAr inhibitors, as well as NR1 antagonists have been largely disappointing (Madden 2002; Warach et al. 2006), partly due to significant side effects (Groenendaal et al. 2002; Levene et al. 1995). New strategies, such as manipulating co-agonist concentrations by influencing enzyme kinetics might form a more subtle alternative. The protective effect of hypothermia, a currently promising method to decrease neuronal damage in asphyxiated infants with severe encephalopathy, might at least in part rely on reducing glutamate (Baker et al. 1991; Illievich et al. 1994) and glycine (Baker et al. 1991; Simpson et al. 1991) concentrations, as observed in rabbit hippocampus microdialysates and in superfusates from rat cerebral cortical slices. Although D-serine concentrations have not yet been investigated in hypothermia, these results show that the reduction of the concentrations of the NMDAr (co)-agonists might be beneficial in global ischemia. Targeting the glycine and particularly the D-serine synthetic pathway may provide an attractive novel treatment option for asphyxiated neonates.

Acknowledgments We gratefully acknowledge financial support from The Netherlands Organization for Health Research and Development (to S.A.F: 920-03-345). We thank Marc Vooijs of the Department of Pathology of the University Medical Center Utrecht for using the hypoxia working station obtained with financial support from the Maurits and Anna de Kock Foundation. We thank Bart van de Sluis and Leyla Tabataye for their expert assistance and helpful discussions.

Conflict of interest The authors declare that they have no conflict of interest.

Open Access This article is distributed under the terms of the Creative Commons Attribution Noncommercial License which permits any noncommercial use, distribution, and reproduction in any medium, provided the original author(s) and source are credited.

\section{References}

Baker AJ, Zornow MH, Grafe MR, Scheller MS, Skilling SR, Smullin DH, Larson AA (1991) Hypothermia prevents ischemia-induced increases in hippocampal glycine concentrations in rabbits. Stroke 22:666-673

Benveniste H, Drejer J, Schousboe A, Diemer NH (1984) Elevation of the extracellular concentrations of glutamate and aspartate in rat hippocampus during transient cerebral ischemia monitored by intracerebral microdialysis. J Neurochem 43:1369-1374

Bergeron R, Meyer TM, Coyle JT, Greene RW (1998) Modulation of $N$-methyl-D-aspartate receptor function by glycine transport. Proc Natl Acad Sci USA 95:15730-15734

Billard JM (2008) D-Serine signalling as a prominent determinant of neuronal-glial dialogue in the healthy and diseased brain. J Cell Mol Med 12:1872-1884

Dobbing J, Sands J (1979) Comparative aspects of the brain growth spurt. Early Hum Dev 3:79-83

Fritz KI, Groenendaal F, Andersen C, Ohnishi ST, Mishra OP, Delivoria-Papadopoulos M (1999) Deleterious brain cell membrane effects after NMDA receptor antagonist administration to newborn piglets. Brain Res 816:438-445

Fuchs SA, Dorland L, der Velden MG, Hendriks M, Klomp LW, Berger R, de Koning TJ (2006) D-Serine in the developing human central nervous system. Ann Neurol 60:476-480

Fuchs SA, der Velden MG, de Barse MM, Roeleveld MW, Hendriks M, Dorland L, Klomp LW, Berger R, de Koning TJ (2008) Two 
mass-spectrometric techniques for quantifying serine enantiomers and glycine in cerebrospinal fluid: potential confounders and age-dependent ranges. Clin Chem 54:1443-1450

Groenendaal F, Rademaker CM, Toet MC, de Vries LS (2002) Effects of magnesium sulphate on amplitude-integrated continuous EEG in asphyxiated term neonates. Acta Paediatr 91:1073-1077

Gucuyener K, Atalay Y, Aral YZ, Hasanoglu A, Turkyilmaz C, Biberoglu G (1999) Excitatory amino acids and taurine levels in cerebrospinal fluid of hypoxic ischemic encephalopathy in newborn. Clin Neurol Neurosurg 101:171-174

Halassa MM, Fellin T, Haydon PG (2007) The tripartite synapse: roles for gliotransmission in health and disease. Trends Mol Med 13:54-63

Huang R, Shuaib A, Hertz L (1993) Glutamate uptake and glutamate content in primary cultures of mouse astrocytes during anoxia, substrate deprivation and simulated ischemia under normothermic and hypothermic conditions. Brain Res 618:346-351

Hur YS, Kim KD, Paek SH, Yoo SH (2010) Evidence for the existence of secretory granule (dense-core vesicle)-based inositol 1,4,5-trisphosphate-dependent $\mathrm{Ca} 2+$ signaling system in astrocytes. PLoS One 5:e11973

Illievich UM, Zornow MH, Choi KT, Scheller MS, Strnat MA (1994) Effects of hypothermic metabolic suppression on hippocampal glutamate concentrations after transient global cerebral ischemia. Anesth Analg 78:905-911

Jones PA, May GR, McLuckie JA, Iwashita A, Sharkey J (2004) Apoptosis is not an invariable component of in vitro models of cortical cerebral ischaemia. Cell Res 14:241-250

Katsuki H, Nonaka M, Shirakawa H, Kume T, Akaike A (2004) Endogenous D-serine is involved in induction of neuronal death by $N$-methyl-D-aspartate and simulated ischemia in rat cerebrocortical slices. J Pharmacol Exp Ther 311:836-844

Lawn JE, Cousens S, Zupan J (2005) 4 million neonatal deaths: when? Where? Why? Lancet 365:891-900

Levene M, Blennow M, Whitelaw A, Hanko E, Fellman V, Hartley R (1995) Acute effects of two different doses of magnesium sulphate in infants with birth asphyxia. Arch Dis Child Fetal Neonatal Ed 73:F174-F177

Madden K (2002) NMDA receptor antagonists and glycine site NMDA antagonists. Curr Med Res Opin 18 Suppl 2:s27-s31

Martineau M, Galli T, Baux G, Mothet JP (2008) Confocal imaging and tracking of the exocytotic routes for D-serine-mediated gliotransmission. Glia 56:1271-1284

Molla G, Sacchi S, Bernasconi M, Pilone MS, Fukui K, Pollegioni L (2006) Characterization of human D-amino acid oxidase. FEBS Lett 580:2358-2364

Mothet JP, Parent AT, Wolosker H, Brady RO Jr, Linden DJ, Ferris CD, Rogawski MA, Snyder SH (2000) D-Serine is an endogenous ligand for the glycine site of the $N$-methyl-D-aspartate receptor. Proc Natl Acad Sci USA 97:4926-4931

Mothet JP, Pollegioni L, Ouanounou G, Martineau M, Fossier P, Baux $G$ (2005) Glutamate receptor activation triggers a calciumdependent and SNARE protein-dependent release of the gliotransmitter D-serine. Proc Natl Acad Sci USA 102:5606-5611

Mustafa AK, Ahmad AS, Zeynalov E, Gazi SK, Sikka G, Ehmsen JT, Barrow RK, Coyle JT, Snyder SH, Dore S (2010) Serine racemase deletion protects against cerebral ischemia and excitotoxicity. J Neurosci 30:1413-1416

Oliet SH, Mothet JP (2009) Regulation of $N$-methyl-D-aspartate receptors by astrocytic D-serine. Neuroscience 158:275-283

Panatier A, Theodosis DT, Mothet JP, Touquet B, Pollegioni L, Poulain DA, Oliet SH (2006) Glia-derived D-serine controls
NMDA receptor activity and synaptic memory. Cell 125:775784

Peeters-Scholte C, Koster J, Veldhuis W, van den Tweel E, Zhu C, Kops N, Blomgren K, Bar D, van Buul-Offers S, Hagberg H, Nicolay K, van BF, Groenendaal F (2002) Neuroprotection by selective nitric oxide synthase inhibition at 24 hours after perinatal hypoxia-ischemia. Stroke 33:2304-2310

Phillis JW, Walter GA (1989) Effect of a brief hypoxic/hypotensive episode on the in vivo release of cerebral cortical gammaaminobutyric acid and glycine. Brain Res 504:121-123

Puka-Sundvall M, Gilland E, Bona E, Lehmann A, Sandberg M, Hagberg H (1996) Development of brain damage after neonatal hypoxia-ischemia: excitatory amino acids and cysteine. Metab Brain Dis 11:109-123

Robertson CM, Finer NN, Grace MG (1989) School performance of survivors of neonatal encephalopathy associated with birth asphyxia at term. J Pediatr 114:753-760

Roldan A, Figueras-Aloy J, Deulofeu R, Jimenez R (1999) Glycine and other neurotransmitter amino acids in cerebrospinal fluid in perinatal asphyxia and neonatal hypoxic-ischaemic encephalopathy. Acta Paediatr 88:1137-1141

Rossi DJ, Brady JD, Mohr C (2007) Astrocyte metabolism and signaling during brain ischemia. Nat Neurosci 10:1377-1386

Sattler R, Tymianski M (2001) Molecular mechanisms of glutamate receptor-mediated excitotoxic neuronal cell death. Mol Neurobiol 24:107-129

Selway LD (2010) State of the science: hypoxic ischemic encephalopathy and hypothermic intervention for neonates. Adv Neonatal Care 10:60-66

Shankaran S, Woldt E, Koepke T, Bedard MP, Nandyal R (1991) Acute neonatal morbidity and long-term central nervous system sequelae of perinatal asphyxia in term infants. Early Hum Dev $25: 135-148$

Shleper M, Kartvelishvily E, Wolosker H (2005) D-Serine is the dominant endogenous coagonist for NMDA receptor neurotoxicity in organotypic hippocampal slices. J Neurosci 25:94139417

Simpson RE, Walter GA, Phillis JW (1991) The effects of hypothermia on amino acid neurotransmitter release from the cerebral cortex. Neurosci Lett 124:83-86

Strisovsky K, Jiraskova J, Mikulova A, Rulisek L, Konvalinka J (2005) Dual substrate and reaction specificity in mouse serine racemase: identification of high-affinity dicarboxylate substrate and inhibitors and analysis of the beta-eliminase activity. Biochemistry 44:13091-13100

Ueda Y, Obrenovitch TP, Lok SY, Sarna GS, Symon L (1992) Changes in extracellular glutamate concentration produced in the rat striatum by repeated ischemia. Stroke 23:1125-1130

Wang LZ, Zhu XZ (2004) Serine racemase expression in mouse cerebral cortex after permanent focal cerebral ischemia. Acta Pharmacol Sin 25:436-441

Warach S, Kaufman D, Chiu D, Devlin T, Luby M, Rashid A, Clayton L, Kaste M, Lees KR, Sacco R, Fisher M (2006) Effect of the glycine antagonist gavestinel on cerebral infarcts in acute stroke patients, a randomized placebo-controlled trial: the GAIN MRI substudy. Cerebrovasc Dis 21:106-111

Wolosker H, Blackshaw S, Snyder SH (1999) Serine racemase: a glial enzyme synthesizing D-serine to regulate glutamate- $N$-methylD-aspartate neurotransmission. Proc Natl Acad Sci USA 96:13409-13414 